\title{
Hoe vertel ik het de Tweede Kamer?
}

\author{
H. Singer-Dekker ${ }^{*}$
}

Het wordt een beetje van beide. Ik wil u eerst iets vertellen over mijn lotgevallen als lid van de Tweede Kamer en daarna zal ik uiteenzetten hoe een burger naar mijn mening de Tweede Kamer het beste zou kunnen benaderen. Want het is zo jammer als iemand wat te zeggen heeft en het komt niet over, doordat de tijd niet in acht genomen is of de manier waarop dat gebeuren moet niet in acht genomen is. Beide onderdelen lopen een beetje in elkaar over.

\section{Hoe kwam ik erin en wat heb ik eraan gehad?}

Ik ben van 1963 tot 1970 lid van de Tweede Kamer geweest als lid van de Partij van de Arbeid. Ik werd in 1962 gewoon opgebeld en toen zei iemand: 'Heb jij zin om in de Tweede Kamer te komen? En ik dacht: 'van mijn leven niet'. Mijn man zei: 'dat doe je dus'. Ik zei: 'ik denk er niet aan'. Afijn dat heeft een week geduurd. En toen had hij me toch zover dat ik dacht: 'nou ja wat kan me nou eigenlijk overkomen? Ik kom natuurlijk toch niet op een verkiesbare plaats.' Dus ik heb toen maar ja gezegd. En die hele periode tot in de Tweede Kamer is van schrik naar schrik gegaan bij mij. Want ik schrok toen ik die verkiezingslijst zag en ik wel op een verkiesbare plaats stond. En toen kwam de verkiezingsdag en op het Parool, waar ik toen werkte, zeiden ze al: 'nou dag kamerlid.' De dag van de verkiezingen was verschrikkelijk. De Partij van de Arbeid had vijf zetels verloren. Dat was toen in 1963 een aardverschuiving. Ik kwam er niet in, maar zou op een eerste opvolgersplaats komen. Ik denk dat ik het enige Partij van de Arbeid lid was dat toen opgewekt naar bed is gegaan met de gedachte: 'die beker is mij voorbij gegaan.' Maar dat bleek toch niet zo te zijn, want er moest er nog geloot worden. Je loot niet zelf maar de lijsttrekker loot, die staat meestal op meer dan een lijst en die moet loten op welke lijst hij nou geacht wordt gekozen te zijn. Dat betekent dat op alle andere lijsten, waar hij ook lijsttrekker is, je allemaal een plaats opschuift. En zo kwam ik er dan toch direct in.

\footnotetext{
Emeritus hoogleraar straf- en strafprocesrecht aan de Rijksuniversiteit Groningen.
} 
Toen ik wist dat ik erin zou komen heb ik tegen mijn man gezegd: 'je weet het, ik heb hier nooit naar gestreefd. Ik wil dit helemaal niet.' En toen zei hij: 'Ja, maar je moet me beloven, dat je de eerste vier jaar zelf niet uitkijkt naar wat anders. Want je hebt vier jaar nodig om dit vak te leren'. En dat is absoluut waar. De verstandigen laten zich het eerste jaar ook nauwelijks horen. Wiegel, die ik in de tweede periode meegemaakt heb, heeft het eerste jaar ook niet veel gezegd. Die was verstandig genoeg om uit te kijken. Je hebt een paar jaar nodig om dit vak onder de knie te krijgen. En ik wilde eigenlijk zo graag naar de universiteit. Na zeven jaar kreeg ik een kans, bij de enige universiteit in Nederland waar ik beslist nooit verwacht had dat ik een kans zou kunnen krijgen en dat was de katholieke universiteit van $\mathrm{Nij-}$ megen. Ik ben gegaan, om de eenvoudige reden dat ik toen al 52 was. Dit was een gouden kans. Ik ben mijn man altijd innig dankbaar gebleven dat hij zo op me gedramd heeft, want ik heb de tijd in de Tweede Kamer enig gevonden. Ik heb er zo van genoten en ik ben nog altijd dankbaar dat ik die ervaringen daar heb mogen opdoen.

'Waarom hebben ze me in vredesnaam toen in 1962 gekozen?', dat vraag je je achteraf wel eens af. Nou het eerste argument ligt voor de hand: ik was een vrouw. Een beetje een vooruitstrevende partij moest vrouwen op zijn lijst hebben. Ik dacht dat ik de eerste keer met vijf vrouwen in die fractie gezeten heb. Dat is natuurlijk minder dan nu, maar het was toch aardig. Het is met die vrouwen ook erg leuk gegaan allemaal. In de tweede plaats had ik ook wel een beetje verstand van sociale verzekering. Ik ben begonnen bij Centraal Beheer, bij de afdeling die nou bij het GAK zit, dus de sociaal juridische afdeling. En ik ben later vijf jaar hoofd geweest van het bestuur van het Bureau voor Arbeidsrecht van het NVV in Amsterdam. Een kwart van de zaken die we daar deden waren sociale verzekeringszaken. Later ben ik dan nog in het bestuur van de sociale verzekeringsbank gekomen en dat was ook ontzettend leuk.

Enige ervaring buiten het gezin is wel van enig nut. Het grappige is dat ik de sociale verzekering kende van verschillende aspecten maar uitgerekend niet van het aspect dat in de Kamer het meest aan de orde komt en dat is natuurlijk op een hoger economisch vlak. Voor de Kamer was de belangrijkste vraag wat de premie van die nieuwe wet zou zijn? Wie betaalt die premie? Wat voor invloed er van de premie uitgaat op de hele Nederlandse economie, op de lonen bijvoorbeeld. De kring der verzekerden is ook erg belangrijk. En de vraag hoe je aan de premie komt. Daarbij is mij het meest opgevallen dat wij leven in een samenleving die wij niet kennen. Je weet niet wat voor wetmatigheden daarin nou eigenlijk werken. Je kunt het niet overzien. Het is leven en lopen in een soort moeras. Je weet nooit precies waar je nou eigenlijk mee bezig bent en wat hetgeen wat je nu beslist straks op zal roe- 
pen. Dat betekent ook dat je een beslissing neemt in een samenleving die je niet kent voor een toekomst die je niet kent. En bij die beslissing schat je in en weeg je af. Je schat in daar zou ik willen komen. En dan ga je de nadelen en de voordelen afwegen, want nadelen zijn er bijna altijd. Welk belang wordt geschaad en welk belang dien ik er mee? En is dat een beetje in evenwicht?

\section{Politiek is gewoon doormodderen}

Het is doormodderen van fout naar fout, van iedere keer weer denken: "was dat nou goed of was dat nou niet zo goed en moeten we dat voortaan niet anders doen?' Gegarandeerd dat als je het anders gaat doen dat je het ook weer fout doet hoor. Ik denk nog aan het woord van Suurhof, zo'n echte oude SDAP'er, ook minister geweest, die zei: 'we kunnen een klein beetje bijsturen, maar verder kunnen we niet veel.' En wat is dan de conclusie en waarom is het nou toch weer zo bijzonder interessant? Dat is dat de democratie een collectief leerproces is. Je leert met je allen. Er wordt over gesproken, er wordt over gedebatteerd, en iedereen denkt van een ander dat hij nonsens zegt. Maar met elkaar kom je toch soms een beetje verder. Dat is het enige wat je er van kan zeggen. Om dat proces mee te maken is toch wel vreselijk leuk.

\section{Marges}

Wat ik daar ook geleerd heb en dat zie ik eigenlijk alle dagen nog, dat de realiteit maakt dat de marges die je hebt veel kleiner zijn dan je zelf dacht. Dat maakt ook dat je als burger die er helemaal buiten staat altijd maar weer denkt: 'kan dat kabinet blijven? Valt het?' En meestal denk ik: 'nou waarom zou dat nou vallen?' Want de realiteit is zo. Er zit natuurlijk wel marge in of je een beetje zo of een beetje zus gaat. Maar er staat altijd wel weer iets tegenover. Een of andere reusachtige schadepost. Ja, je kunt in die marge wat modderen maar dan moet je wel bedenken dat je dat moet betalen. En daardoor denk ik dat die kabinetten ook best lang kunnen bestaan. Maar soms vallen ze over iets waar je nou helemaal niet aan gedacht hebt. Ik denk aan het kabinet Marijnen dat viel, dat implodeerde. Dat viel over de omroep. Dat was door weinig mensen voorspeld. Ondanks de smalle marges, die je haast tot een bepaalde oplossing dwingen, kan toch soms onverwacht geen oplossing worden gevonden. Het hangt ervan af of de mensen het met elkaar kunnen vinden in zo'n kabinet. Zo lang dat zo is, vinden ze wel een compromis. 
Als ze op elkaar uitgekeken zijn valt een kabinet soms over een probleem dat door geen buitenstaander als een struikelblok was gezien. Dat is mijn conclusie uit zeven jaar kamerlidmaatschap.

\section{Hoe vertel ik het de Kamer?}

Allereerst wil ik erop wijzen dat de Tweede Kamer goed bereikbaar is. Er is een lijst van de leden met hun e-mailadressen, hun fax, hun telefoon, hun adres, hun partij, het bezoekadres, postadressen van de Tweede Kamer zelf. Het is gratis verkrijgbaar bij de Tweede kamer.

Toen ik in Tweede Kamer zat heb ik gemerkt dat veel mensen zich op een manier tot de Kamer wendden dat je zegt: 'ja nou kan ik er niks meer mee doen.' Maar ik ben veel later pas in de gelegenheid geweest om dat wat nader uit te werken. Een ding vooraf. Parlementsleden willen altijd goed ingelicht worden, willen altijd informatie aanhoren en moeten ook wel. Want je wordt iedere keer weer opgebeld en je hebt het hart niet in je lijf om te zeggen: 'nee, ik wil u niet te woord staan.' Dat kon helemaal niet. Burgers bellen je om je te vertellen dat je het helemaal fout doet en als je het nou doet zoals zij dat willen dan gaat het helemaal goed. Ze willen ook best bij je komen om je even te vertellen hoe je dat nou doen moet. Maar even later word je opgebeld door een ander die ongeveer hetzelfde verhaal heeft, alleen daarvoor moet je het dan weer anders doen. Toch moet je die mensen te woord staan. Anders staat morgen in de kranten: 'ze wou niet eens met me spreken.' Je moet je dus goed realiseren dat de kamerleden altijd informatie willen. Het is jammer als het niet kan werken omdat je veel te laat komt. Een Kamerlid drukte dat vele jaren later voor de radio eens goed uit, zij zei: 'weet u wat ik nou zo beroerd vind, dan krijg je de avond voor de openbare behandeling van een wetsontwerp van een of ander middelgroot bedrijf een verhaal over dat wetsontwerp en een pasklaar amendement.' Dat kan absoluut niet. Je kan niet zomaar plompverloren een amendement gaan indienen. Waarom kan dat niet? Omdat een van de allermoeilijkste dingen is een amendement te maken. Voordat ik in de Kamer kwam vertelden ze mij al, Vondeling was daarbij, 'denk eraan een amendement laat je maken door degene die het wetsontwerp gemaakt heeft, door die ambtenaar. Je gaat naar het ministerie toe, je zegt meneer hebt $\mathrm{u}$ dat wetsontwerp, ik wou er dat in hebben. Wilt u het maar voor mij maken?' Het is verreweg de beste manier, dat kun je bijna niet zelf. Maar ze sturen je dat uitgerekend de dag voor de openbare behandeling. En dat is het eindstation van een hele lange voorbereiding meestal, terwijl iedereen al weet waar je staat, als eigenlijk alles is uitgekauwd en doorgesproken. Als het absoluut nodig kan het wel, want er 
kan ook bijna altijd aan de termijn veranderd worden als de Kamer het goed vindt. En de Kamer is erg prettig met die dingen. Die wil altijd een ander wel de kans geven. Iedere partij weet immers dat zij ook in zo'n situatie terecht kan komen.

\section{Een enquête}

Ik heb zowat 25 jaar rondgelopen in een of ander bestuur van de reclassering. De reclassering wist de Kamer wel te vinden. Daar gingen prachtige adressen naar de minister, afschrift Kamer, en voor de begroting altijd netjes een heel verhaal naar de Kamer. Dat was allemaal goed voor elkaar. Alleen, ik las die dingen en ik dacht: 'ja maar, dat gaat zo niet, daar bereik je niks mee.'

Een jaar of tien geleden - ik was toen al 20 jaar uit de Kamer - heb ik dat eens tegen Leo Witvliet, de landelijk directeur gezegd en die vond dat interessant. Toen ben ik het de Kamerleden eens gaan vragen. Ik heb de fracties allemaal opgebeld en ik heb ze gevraagd wie bij hun de Reclassering in zijn portefeuille had. Met die mensen heb ik gesproken. Van twee fracties heb ik geen kamerlid gesproken maar een medewerker en dat was ook erg leuk. Want ja, ik ben nog van de tijd dat je helemaal geen medewerkers had.

\section{Informatieverschil tussen Kamer en Minister}

Daar is er wel verandering in gekomen en in mijn tweede periode beschikte de hele fractie van de PvdA over twee medewerkers. Dat waren Hans Ouwerkerk en Aad Kosto. Als je dat vergelijkt met wat dat nu is, dan is het wel een groot verschil. Overigens houd je altijd dat verschil in informatie tussen de minister en de Kamer. Want hoe groot je dat bureau van de Kamer nou ook maakt, je kunt natuurlijk nooit op tegen al die ministeries die allemaal meestal ook zeer goede - deskundigen in dienst hebben, waar de minister op kan steunen en waar hij ook op hoort te kunnen steunen. Daar kan je als Kamerlid nooit tegenop. Daarom zijn ze ook dolblij als ze informatie kunnen krijgen langs nog een andere weg. En als dat mensen zijn waarvan bekend is dat ze het echt weten dan nemen ze die informatie graag aan. Ik moet ook zeggen dat de commissies waarin de Kamer verdeeld is iedereen kan horen die ze willen. Daar maken ze ook gebruik van. Ik herinner me wel, dat wij dat gedaan hebben, vooral bij de antibioticawet. Jan Lammers was de arts in onze fractie en hij was ook voorzitter van die commissie en toen heb- 
ben we daar deskundigen over gehoord. Maar op de één of ander manier sta je toch achter bij de minister.

\section{Wat kwam er uit die enquête?}

Ze zeiden allemaal - op een na; mevrouw Haas-Berger wist er ook werkelijk wat van - dat ze niets van de Reclassering wisten en dat ze er zo vreselijk graag wat vanaf wilden weten. Ja, dat hoor je dan als je jarenlang die Kamer hebt bestookt. Dat kwam omdat ze het niet op een goede manier hadden aangepakt.

\section{Drie momenten}

Je hebt drie gevallen waarin je als gewoon mens met bepaalde kennis van zaken de Kamer kunt inlichten. Dat is in de eerste plaats bij de behandeling van een wetsontwerp, in de tweede plaats bij de begroting en in de derde plaats bij incidenten. Bij het wetsontwerp moet je je natuurlijk houden binnen de grenzen van het wetsontwerp. Men neemt dat vrij ruim maar het moet natuurlijk wel iets te maken hebben met de stof die dat wetsontwerp behandelt. Bij de begroting wordt veel meer aan de orde gesteld. Daar wordt het hele beleid aan de orde gesteld van die minister van dat departement. Dan kun je eens vragen of daar niet eens een onderzoek naar kan worden ingesteld en of de minister eens eraan zou willen denken om dat en dat te regelen. Als voorbeeld van een incident denk ik aan de hype die we onlangs hebben gehad met die pedoseksuelen. Het werd te dol. Je kunt nu op het internet vragen of er in jouw wijk een pedoseksueel woont. En er werd voorgesteld de proeftijd tot 15 jaar te verlengen. Nou er zijn toch wel mensen, en zeker in onze kring, die daar nou eens wat over kunnen zeggen. En die ook een gevoel krijgen: 'dan moet ik ook eens laten weten wat ik daarover denk. Want dit wordt toch een beetje te dol.' Daar kun je dan ook echt wel een oor voor vinden. Dat zie ik als drie momenten waarop de burger kan laten blijken wat hij ervan vindt.

\section{Het wetsontwerp}

Daar loopt het dikwijls mis; dat bleek ook heel sterk uit dat onderzoekje. De informatie van de burger komt te laat. Met het wetsvoorstel dienstverlening is het bij de Reclassering overigens heel goed gelopen. Uiteraard heb ik toen ook in de Federatieraad gezegd dat het wetsontwerp er was en dat we als de bliksem een commissie moesten instellen die dat wetsontwerp doorloopt en 
die gewoon artikel voor artikel zegt wat ze er van vindt. Dat is gebeurd. Dat rapport is op tijd ingeleverd en 'op tijd' betekent dus minstens enige weken voor de inbreng van de fracties voor het Voorlopig Verslag.

Als een wetsontwerp binnenkomt bij de Kamer dan beslist het Presidium naar welke commissie het gaat. Dienstverlening ging natuurlijk naar de vaste commissie van justitie. Ze benoemen ook wel eens een bijzondere commissie, bijvoorbeeld bij de Krankzinnigenwet die er toen nog was. Alles over dwangopname gaat altijd naar een bijzondere commissie en dat is dan Volksgezondheid en Justitie. Er zijn natuurlijk onderwerpen die gecombineerd behandeld moeten worden, waar niet zomaar direct een vaste commissie voor is. De commissie beslist wanneer de inbreng voor het Voorlopig Verslag is. Dat betekent dat ze de informatie ook weer niet de avond voor die inbreng moeten krijgen, maar een behoorlijk tijdje daarvoor zodat het echt mee kan tellen. Dat is bij het wetsontwerp dienstverlening heel goed gelopen.

Ik heb in mijn onderzoekje alle kaderleden gevraagd wat ze daar nou van vonden. Nou ze jubelden. De fractie medewerkster van D'66 zei: 'mevrouw dat was iets heerlijks, je kon het zo als inbreng gebruiken voor het Voorlopig Verslag'. Dat is wat Kamerleden nodig hebben. Het wil natuurlijk niet zeggen dat ze alles overnemen. Maar je ziet dat die inbreng wel degelijk kan helpen. Als je het maar op de goede tijd doet. Bij een wetsontwerp - zo druk ik u op het hart - moet u uw bijdrage vooral enkele weken voor de inbreng voor het Voorlopig Verslag indienen.

En dan het amendement. Daar heb ik wel een verhaaltje over. Ik heb eens zo vreselijk gelachen.

\section{Vrolijkheid in de Kamer}

Je lacht wat af in de Kamer. Een heleboel mensen kunnen dat niet begrijpen. Maar het is toch echt waar. Ik kreeg ook nog eens een reactie van iemand: 'ik vond het zo leuk dat je zei dat je er zoveel gelachen had; ik dacht dat jullie helemaal geen gevoel voor humor hadden.' Nou, dit is werk dat je beter niet kan doen als je geen gevoel voor humor hebt, want dan is het niet uit te houden. Je moet ontzettend veel kunnen lachen. We hebben het eens gehad, ik weet helemaal niet meer waarover het ging, maar we kregen tien minuten schorsing, 's avonds om twaalf uur, voor fractieberaad over een motie. Een motie natuurlijk van een ander dan van je eigen partij want voor jezelf heb je dat beraad natuurlijk allang gehouden. En ik zie ze nog tegenover elkaar staan in de fractie, Dirk Roemers en Theo van Lier. Zij stonden op van hun stoelen. En ik dacht: 'die vliegen elkaar aan.' Op dat moment zei 
iemand wat geks en de hele fractie schoot in een lach, en toen gingen ze allebei zitten en toen konden we weer verder. Zo werkt het.

\section{Het amendement}

Dat wat ik met een amendement meegemaakt heb is het volgende. Er was een militaire weduwewet aan de orde. En de weduwe dat is iets, dat is het troetelkind van ieder parlement, want ze is zielig en ze is fatsoenlijk. Daar gaan we vanuit. En dat is fijn, dat kan je vertroetelen. En het was een mooie wet, de hele Kamer was het er over eens, de weduwen kregen het dan veel beter en dat was mooi en dat zou dus aangenomen worden. Maar wie moest dat nou behandelen? Het was een militaire weduwewet. Dus het werd behandeld door de Minister van Defensie. Dat was toevallig De Jong, en De Jong was een reuze vent. Daar gingen verhalen over, dat hij duikbootkapitein was geweest en dat het personeel van de marine onder elkaar vocht om onder De Jong te mogen dienen. Ik kan het me voorstellen, het was een vreselijk aardige man. En De Jong behandelde die wet. Bij ons deed dat een militaire deskundige, Wiebe Wierda ook een reuze leuke vent. En die twee hebben kenden elkaar waarschijnlijk al goed. Over politieke heggen heen kan ook nog wel vriendschap ontstaan. Maar Wiebe had natuurlijk de hulp van Wout van der Gevel en of hij toen al lid was van de fractie dat weet ik niet. Maar in ieder geval, hij kwam uit de ambtenarenbond en daar was zijn taak al de pensioenen. Die wist van de hoed en van de rand. En die heeft Wiebe daarin geassisteerd. Wout zei tegen Wiebe dat er nog een amendement gemaakt moest worden. Wout maakt het en Wiebe diende het in. Het was een prachtig amendement, en de hele Kamer was het er weer mee eens, want dan kregen de weduwen het nog mooier. En toen kwam De Jong en die zei dat het heel mooi was en dat het ook moest gebeuren. Maar ja het moeilijke van een amendement is natuurlijk dat de formulering precies moet kloppen met de andere artikelen van die wet. En als je daar dan een fout mee maakt, dan kan je die wet helemaal ondergraven en dat is iets afschuwelijks. Wout van der Gevel zou het best goed gedaan hebben, maar ja het kan toch altijd beter. En toen zei De Jong dat hij het er helemaal mee eens was maar dat we moesten uitkijken dat het goed geformuleerd was en hij vroeg aan meneer Wierda of die dat amendement toch maar wilde intrekken. Het wetsontwerp kon rustig aangenomen worden en ook in werking treden. En De Jong beloofde dat hij zo snel mogelijk daar achteraan nog weer een wijzigingswetje zou sturen om dat amendement - maar dan helemaal geformuleerd zoals het moest - er ook weer in te krijgen. Toen kwam Wiebe weer en dat was een droogkomiek hoor, die kon dan zo'n fijn lachje hebben en hij zei tegen de Minister dat hij niet begreep dat het zo moest. 'Ja, maar', zei die minister 'het is zo jammer om die weduwe, om die arme zielen daar nou 
op te laten wachten'. Want dan zou het wat later worden. En dat wilde hij voorkomen. 'Nou dat is toch helemaal geen bezwaar' zei Wiebe, 'de minister zet zijn ambtenaren een week in een hotel en hij zegt gewoon: je komt er niet uit zolang dat niet klaar is. Ze doen er misschien veertien dagen over, maar dat kan toch geen bezwaar zijn.'

De Jong zag dat hij het zo niet redde. Daar was hij al op voorbereid en hij trok uit die stapel die hij voor zich had een papier en hij zei: 'als meneer Wierda er dan op staat, wil ik toch nog vragen of hij even wil kijken of hij zijn amendement niet zo kan wijzigen als op dit papier staat.' Hij zei erbij: 'vraag me niet wat er in staat meneer de voorzitter, want het is voor mij zo helder als het binnenste van een computer'. En dat was het. Toen vroeg Wiebe tien minuten schorsing van de beraadslaging om te kijken of het zo nog beter was en Wout zei: 'Ze hebben gelijk'. Zo is het nog mooier, dus daar kun je wel mee akkoord gaan, maar dan moeten we effe een geintje hebben, hè? Nou moet je hem dit vragen - het was iets ingewikkelds, HSD en dan zeg je maar dat je voordat je nou helemaal beslist eerst nog antwoord wilt hebben op die vraag. Wiebe speelde dat helemaal mee; die heeft waarschijnlijk ook niet geweten wat hij toen voorlas. Let wel, dit is 's avonds om een uur of twaalf dus dan is de pers ook al weg. Hij zei dat hij blij was dat het zo opgelost kon worden en dat hij ook wel dacht dat het zo kon, maar dat hij voordat hij definitief besliste toch nog een antwoord van de minister wilde hebben op deze vraag. De Jong heeft direct gemerkt dat het een geintje was. Ik zat in het oude Kamergebouw. De minister zat tegenover de voorzitter en daarboven was de ambtenarengalerij en die kon dus rechtstreeks de minister aankijken. Je had ook van die mandjes aan katrolletjes waarin de briefjes naar boven en naar beneden gingen. En ik zag een hele beweging in die ambtenarengalerij. Die dachten: 'mijn God als hij dat moet beantwoorden, dan gaat het mis.' Eén van die ambtenaren boog zich naar voren om de aandacht van de minister te trekken. En de Minister keek niet naar zijn ambtenaar. Die boog zich zo ver over die balustrade en stond zo te wijzen naar de Minister dat hij kijken moest. De Jong deed dat niet. Ik zat werkelijk in spanning en ik dacht: 'als hij zich nou nog een centimeter meer over die galerij buigt, dan valt hij eruit. Dan valt hij op het hoofd van de voorzitter.' De Jong keek niet naar zijn ambtenaren en gaf een prachtig antwoord, waarop Wiebe zei, dat hij die minister dankte voor zijn deskundig antwoord. Het amendement werd veranderd zoals De Jong had voorgesteld en aangenomen.

\section{De begroting}

Daarbij geldt eigenlijk hetzelfde. Je moet op tijd zijn, behoorlijk voordat die begroting behandeld wordt. Sommige instellingen, zoals het NVV deden dat bijzonder goed. Ik was in de fractie belast met de vrouwenlonen, de gelijke 
beloning. Dan werd ik altijd opgebeld door de mevrouw die daar bij het NVV zat voor de vrouwen. Die zei dan zo in juli of augustus: 'Hanny, wat wil je voor gegevens hebben, dan zal ik proberen die boven water te krijgen en wanneer kunnen we er dan over praten voor de begroting?' Dat deed ze heel zakelijk, en dan kreeg ik ook alle gegevens waar ik zelf om had gedacht. En zij had natuurlijk aan nog veel meer gedacht. Dus kreeg ik er een heleboel bij. En zo kun je natuurlijk heel goed met elkaar samenwerken. Dan heb je er echt ook wat aan.

\section{De incidenten}

Bij incidenten is de timing natuurlijk moeilijk. Dan moet je de kamerleden gewoon maar opbellen. Je moet wel de goede hebben. De Kamer verwijst wel door, maar je kunt het zelf ook wel uitzoeken. Je kunt bijvoorbeeld de fractie opbellen. Je kunt ook de commissie opbellen. Of je kunt het op schrift zetten en aan de griffier van de commissie vragen of hij ervoor wil zorgen dat de goede het krijgt. Maar je moet wel direct reageren. Daar valt in het algemeen niet zo erg veel over te zeggen. Wel een paar andere dingen. Wat die Kamerleden tijdens mijn enquête ook allemaal zeiden en daar hebben ze ook gelijk in, 'kort en zakelijk, alsjeblieft. Op een A4-tje als het kan en hoogstens op twee A4-tjes en geen ideologie.' Dat was natuurlijk de fout van de Reclassering. Die ging wazige verhalen houden waar je als Kamerlid weinig aan hebt. Het is niet dat je daar niet in geïnteresseerd bent, maar dat weet je allemaal wel. Als je eenmaal in die Kamer staat dan gaat het om beslissingen. En die beslissingen moeten toch op zakelijke gronden genomen worden. En liefst moet je er dan bij zeggen dat je hebt uitgerekend hoeveel het kost. Want je moet goed weten dat dingen geld kosten. Dat niet alles altijd maar kan, omdat je het ook nog betalen moet. Zo is dat nou eenmaal. Bovendien moet je de Kamerleden niet irriteren door te zeggen dat ze alles fout doen. Dan gaat je stuk de prullenmand in. Dat is logisch. Vooral als je dan ook nog blijk geeft geen flauwe notie te hebben van hoe het in feite werkt. Dus geen ideologie, kort en heel zakelijk formuleren. En wat je dan nog nodig vindt dat ze echt eens zouden moeten lezen, doe je er als een bijlage bij. Dat kan natuurlijk óók teveel zijn. Want de bibliotheek van de Kamer is geweldig. De medewerkers willen je altijd helpen. Met slechts een paar vage gegevens hadden ze gegarandeerd binnen een half uur het gevraagde krantenartikel gevonden. Het is nu misschien anders, maar ik denk toch dat die dienstverlening blijft. Want ik heb niet anders gezien in de Kamer dan dat de jongste bode en iedereen ervan overtuigd was dat het Parlement ván het volk, dóór het volk en vóór het volk is. Het wordt altijd met 
evenveel égards behandeld. De medewerkers zijn vriendelijk en ze zullen altijd alle mogelijke paden bewandelen om jou als burger te geven waar je behoefte aan hebt. Werkelijk heel erg plezierig.

Bij een begroting kan je ook wel eens vragen of er aandacht aan een bepaald rapport besteed kan worden. Dat moet je vooral bij de vaste commissie voor die begroting naar voren brengen. Mevrouw Junger-Tas heeft bijvoorbeeld een paar jaar geleden een voortreffelijk rapport uitgebracht. Ik heb altijd het gevoel dat de regering dat ook wel gevonden heeft, maar dat het alleen niet zo eenvoudig was om uit te voeren. Zij zei: 'de neiging tot misdaad ontstaat ongeveer tussen het tweede en het achtste levensjaar. En als je later bent met ingrijpen loopt dat heel vaak toch weer op niks uit, gewoon omdat het te laat is.' Alleen, ja, ga daar maar eens aandacht aan besteden want wat doe je met een kind tussen de twee en acht? Het strafrecht, daar heb je dan natuurlijk nog niks aan. En je kunt die ouders ook niet dwingen. Maar ik heb toch wel gemerkt dat men soms probeert die ouders heel jong te benaderen, op basis van vrijwilligheid. Want ouders zitten er zelf toch immers mee. Toch steun bieden, en dan gaat die steun ook iedere keer weer fout omdat je de goede methode niet hebt. Het blijft een verschrikkelijk geprobeerd. Maar ik denk dat het heel belangrijk is dat het gebeurd. Laat ik terugkeren naar het onderwerp.

Ik denk ook dat als uit die burgerij blijkt dat men op de hoogte is en het plan goed vindt, men eerder denkt: 'ja daar moeten we nou ook echt wat aan doen.' Dat geeft steun aan de Minister en aan de Kamerleden en dan kun je toch echt wel wat bereiken.

Tenslotte heb ik de kamerleden gevraagd wat ze wilden dat de Reclassering voor hen deed. En ze zeiden allemaal: 'We willen graag eens met ze praten. We willen zo graag eens een inrichting bezoeken en er dan een hele dag zijn.' Dat laatste begrijp ik wel want dan kunnen zij zelf ook vragen stellen. Dan kom je in dialoog met elkaar. Ik vond het erg leuk te horen. Als je met die mensen uit het veld een lunch gebruikt kun je als Kamerlid natuurlijk ook over van alles en nog wat praten. Je moet natuurlijk wel bedenken wat het beste moment is. In ieder geval bijna nooit in begrotingstijd. Als je ze in september uitnodigt dan mag je blij zijn als ze aan het eind van het jaar ook geweest zijn en in hun hoofd hebben wat ze bij de volgende begroting aan de orde kunnen stellen.

Als je zegt: 'we nodigen je uit in de Mesdaginrichting', kun je er donder op zeggen dat ze komen. Je moet niet teleurgesteld zijn als er dan vier of vijf mensen komen. Want niet alle leden van de commissie van Justitie zijn daarin geïnteresseerd. Maar als er een van de PvdA is dan is de fractie van 
de PvdA er. Zo moet je het bekijken. Dat is op persconferenties ook vaak zo. Daar zie je dikwijls heel weinig mensen, maar die weinige mensen bestrijken wel een zeer groot gebied. Daar moet je niet van terugschrikken. Je kunt altijd twee dingen doen. Je kunt de fracties opbellen, maar ja dan moet je iedere fractie natuurlijk opbellen. En je kunt de griffier van de vaste commissie opbellen en dan zul je zien dat ze altijd erg bereid zijn om je verder te brengen. Laat eventueel de Kamerleden zelf maar zeggen wanneer ze kunnen komen. En vraag wat ze nou precies zouden willen horen; waarover ze graag inlichtingen zouden willen hebben.

Even een voorbeeld Een bezoek aan een zwakzinnigeninrichting in Ermelo heeft een hele diepe indruk op ons gemaakt. Je gaat toch anders tegenover dingen staan. Het merkwaardige was dat ze in Ermelo nooit tekort aan personeel hadden. Daar waren mensen twintig jaar in dienst en ik dacht: 'hoe is het mogelijk, dat die mensen het hier zo lang kunnen volhouden.' Wat je daar ziet is hartverscheurend. Maar het personeel was aan die zwakzinnigen gehecht; dat is me toen zo bijgebleven. Ik vertel dat, omdat ik uit eigen ervaring weet hoe diepe indruk dat kan maken.

\section{Elise op de schotsen}

Als u mij vraagt wat ik niet zo prettig vond in de Kamer dan kan ik het volgende zeggen.

Je hebt weinig gelegenheid je eens rustig in een onderwerp te verdiepen. Je rent van de ene actualiteit naar de andere. Dat heeft het Kamerwerk gemeen met de journalistiek. Ik moest dan altijd denken aan een plaat in het beroemde boek De Negerhut van Oom Tom. Die plaat van Elise die bij haar vlucht sprong van de ene ijsschots op de andere. Dat geren achter de actualiteit aan heeft ook het gevaar van vervlakking. Aan de universiteit kreeg ik die gelegenheid wel. Ik heb daarvan ook gebruik gemaakt door mijn dissertatie te schrijven. Het onderwerp daarvan heb ik in de Tweede Kamer gevonden. De justitiële documentatie was een zaak waar geen Kamerlid iets van wist. De Minister trouwens ook niet. Het kwam in de actualiteit door de Maagdenhuisprocessen. 